\title{
Eleições Municipais de 2016 em Araucária
}

\author{
Adriane dos Santos Ferrari Tavella ${ }^{1}$
}

- Enviado em 15/09/2016

- Aprovado em 18/09/2016
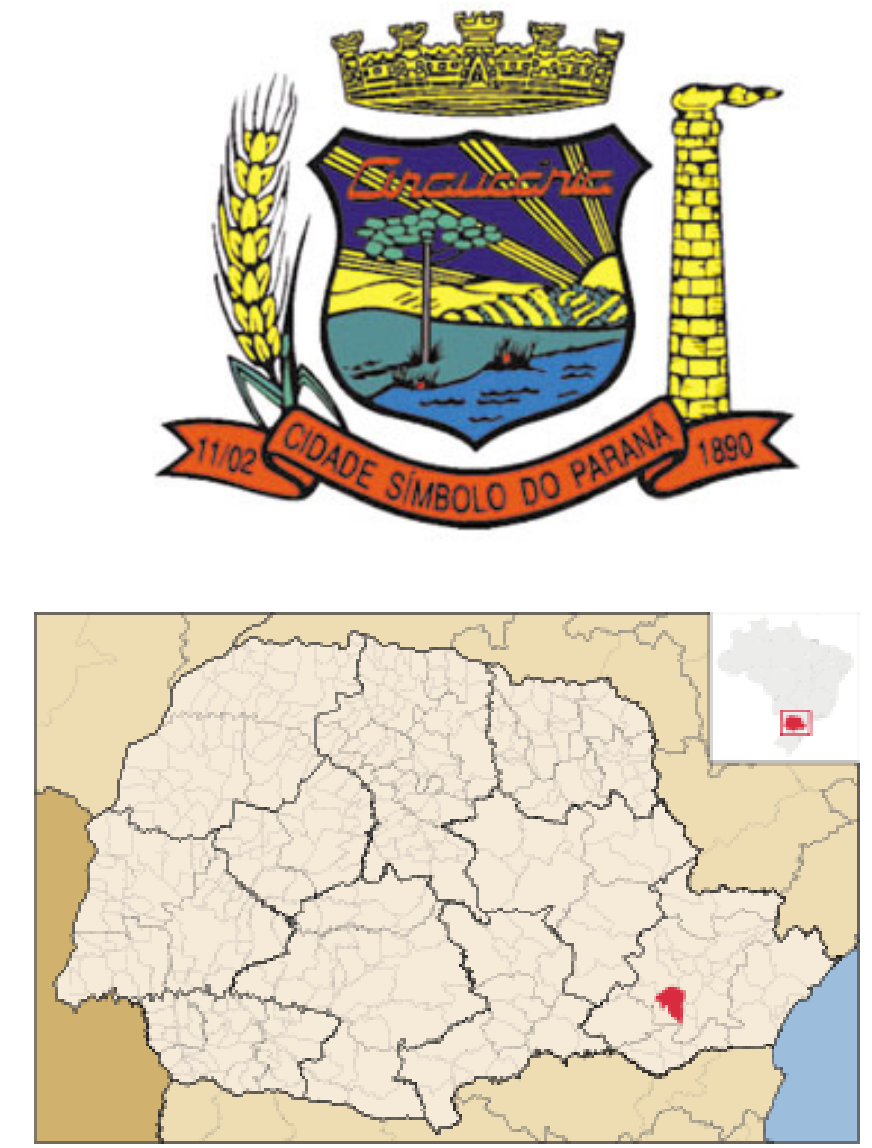

Fonte: $\quad$ http://portaldearaucaria.com.br/conhecaaraucaria/. Acesso 18.setembro.2016

1 Professora da Secretaria de Educação do Paraná. Endereço eletrônico: adrianeferrari2045@gmail.com 


\section{Eleições de 2016 em Araucária}

Adriane dos Santos Ferrari Tavella

O município de Araucária está localizado na região metropolitana de Curitiba há 27 km da capital paranaense. Atualmente possui uma população estimada de 135.459 segundo estimativas do IBGE (instituto Brasileiro de Geografia e Estatística). Nas eleições municipais de 2016, o número de eleitores aptos é de 86.812, segundo dados do Tribunal Eleitoral do Paraná (TRE-PR).

Para as eleições municipais de 2016, o número de candidatos ao cargo de prefeito são ao todo sete, a saber:

1. Rui Sergio de Souza (PTC) atual prefeito assumiu o cargo em 28 de julho de 2016 com a renúncia, do ex-prefeito Olizandro Ferreira, do PMDB que afastou- se por motivos de saúde. Candidato pela coligação "Você do lado certo" tem como vice Pedrinho da Gazeta (PMDB) com o apoio dos seguintes: PP, PSL, DEM, PSC, PPL, PDT e PSB .

2. Rosane Ferreira (PV) foi candidata a vice-governadora na chapa do senador Requião nas últimas eleições de 2014. Deixou seu cargo de deputada federal em março de 2015 para voltar a trabalhar como enfermeira em um posto de saúde do município. Tem como vice Alex Nogueira (PSDB) com a coligação "Araucária em boas mãos" com o apoio dos partidos: PTB, PSDC, PSD, PEN e PRP.

3. Hissam Husseim Dehaine e sua ex-cunhada Hilda Lukalski ambos do PPS na coligação "Com a força do povo vamos trabalhar por uma cidade feliz" e com o apoio dos partidos: PR, PRB, $P C, P C$ do $B, P T$ do $B$ e PMN.

4. Clodoaldo Pinto Junior (PROS) várias vezes secretário de obras do município entre 2001 a 2014. Foi vice-prefeito de 2005 a 2008. Candidato pela coligação "Faxina total" tendo como vice Adriana Cocci (PTN) que deixou seu cargo de vereadora para concorrer como vice, e estão com a coligação com o PMB

Porém, no dia 12 de setembro, Adriana Cocci renunciou sua candidatura. Segundo o Ministério Público a candidata não cumpriu com a legislação eleitoral, em que os membros que 
participam de conselhos devem afastar-se desses órgãos três meses antes das eleições. A candidata Adriana Cocci não teria se desligado em tempo hábil, do Conselho Municipal dos Direitos da Pessoa Idosa e o Ministério Público entrou com o pedido de impugnação da sua candidatura. Antes mesmo da análise do pedido de impugnação, Adriana Cocci optou pela renúncia pois, em caso de vitória, a chapa ficaria impedida de assumir. No lugar da candidata assume seu filho Vinicius Cocci pelo PTN aos 23 anos, nunca participou de uma eleição.

5. Eliseu Palmonari (PRTB) foi candidato a deputado estadual em 2014 pelo partido PRP. Tem como vice Honório da farmácia PRTB. Estão sem apoio de legendas.

6. Rivadal Padilha e vice José Carlos da Cruz, ambos pelo PT sem coligações.

7. Orivaldo José Augusto (PHS) professor aposentado da rede estadual de ensino no município, está na coligação "Paixão por Araucária" com o vice Danilo Donoso (REDE) empresário. Contam com o apoio do partido PSDC.

QUADRO COM OS CANDIDATOS A PREFEITO DE ARAUCÁRIA - PLEITO DE 2016

\begin{tabular}{|c|c|c|c|c|c|}
\hline Candidatos a prefeito & Partido & Idade & $\begin{array}{l}\text { Grau de } \\
\text { instrução }\end{array}$ & Ocupação & Naturalidade \\
\hline $\begin{array}{lll}\text { Cleusa } & \text { Rosane } & \text { Ribas } \\
\text { Ferreira } & & \\
\end{array}$ & PV-43 & 53 anos & $\begin{array}{l}\text { Superior } \\
\text { completo }\end{array}$ & Servidor público & Clevelândia-PR \\
\hline $\begin{array}{l}\text { Clodoaldo Nepomuceno } \\
\text { Pinto Júnior }\end{array}$ & PROS-90 & 61 anos & $\begin{array}{l}\text { Superior } \\
\text { completo }\end{array}$ & engenheiro & $\begin{array}{c}\text { União da Vitória- } \\
\text { PR }\end{array}$ \\
\hline Eliceu Palmonari & PRTB-28 & 56 anos & Ensino Médio & administrador & $\begin{array}{c}\text { Siqueira Campos- } \\
\text { PR }\end{array}$ \\
\hline Hissam Husseim Dehaine & PPS-23 & 59 anos & $\begin{array}{l}\text { Ensino Médio } \\
\text { incompleto }\end{array}$ & empresário & São Paulo-SP \\
\hline Orivaldo José Augusto & PHS-31 & 62 anos & $\begin{array}{l}\text { Superior } \\
\text { completo }\end{array}$ & $\begin{array}{l}\text { Servidor público } \\
\text { civil aposentado }\end{array}$ & Campo Largo-PR \\
\hline Rivadal Donizete Padilha & PT-13 & 58 anos & $\begin{array}{c}\text { Ensino } \\
\text { fundamental } \\
\text { completo }\end{array}$ & $\begin{array}{l}\text { Aposentado não } \\
\text { servidor público }\end{array}$ & Faxinal-PR \\
\hline Rui Sergio Alves de Souza & PTC-36 & 52 anos & $\begin{array}{l}\text { Superior } \\
\text { Completo }\end{array}$ & prefeito & Araucária-PR \\
\hline
\end{tabular}

Elaboração da autora 
QUADRO COM OS CANDIDATOS A VICE-PREFEITO DE ARAUCÁRIA - PLEITO DE 2016

\begin{tabular}{|c|c|c|c|c|c|c|}
\hline Candidato a vice & Partido & Idade & $\begin{array}{c}\text { Grau de } \\
\text { instrução }\end{array}$ & Ocupação & Naturalidade & Chapa com \\
\hline Alex Luiz Nogueira & PSDB-43 & 38 anos & $\begin{array}{c}\text { Superior } \\
\text { incompleto }\end{array}$ & Empresário & Araucária-PR & $\begin{array}{l}\text { Rosane } \\
\text { Ferreira }\end{array}$ \\
\hline $\begin{array}{l}\text { Vinicius Moraes de } \\
\text { Castro }\end{array}$ & PTN- & 23 anos & $\begin{array}{c}\text { Médio } \\
\text { completo }\end{array}$ & Empresário & Araucária-PR & Clodoaldo \\
\hline $\begin{array}{l}\text { Marco Antonio } \\
\text { Honório }\end{array}$ & PRTB-28 & 46 anos & $\begin{array}{l}\text { Ensino } \\
\text { médio } \\
\text { completo }\end{array}$ & Comerciante & Curitiba-PR & Palmonari \\
\hline $\begin{array}{ll}\text { Hilda } & \text { Lukalski } \\
\text { Seima } & \end{array}$ & PPS-23 & 71 anos & $\begin{array}{l}\text { Ensino } \\
\text { médio } \\
\text { completo }\end{array}$ & $\begin{array}{c}\text { Servidora } \\
\text { pública } \\
\text { estadual }\end{array}$ & Araucária-PR & Hissam \\
\hline $\begin{array}{l}\text { Danilo Gobbo } \\
\text { Donoso }\end{array}$ & REDE-31 & 29 anos & $\begin{array}{l}\text { Superior } \\
\text { completo }\end{array}$ & Empresário & São Paulo-SP & $\begin{array}{l}\text { Professor } \\
\text { Orivaldo }\end{array}$ \\
\hline José Carlos da Cruz & PT-13 & 68 anos & Lê e escreve & $\begin{array}{l}\text { Mecânico de } \\
\text { manutenção }\end{array}$ & Castro-PR & Rivadal \\
\hline $\begin{array}{lll}\text { Pedro Ferreira de } \\
\text { Lima }\end{array}$ & PMDB-36 & 49 anos & $\begin{array}{c}\text { Ensino } \\
\text { médio } \\
\text { completo }\end{array}$ & vendedor & Araucária-PR & Rui \\
\hline
\end{tabular}

Elaboração da autora

Sites Consultados:

www.eleições2016.com.br. Acesso em 18 de setembro de 2016.

www.ibge.gov.br. Acesso em 18 de setembro de 2016.

www.justiçaeleitoral.jus.br._Acesso em 18 de setembro de 2016. 